\title{
Characterization of non-metallic inclusions in corrosion - resistance nickel - based EP718 and 718 alloys by using electrolytic extraction method
}

\author{
Andrey Karasev ${ }^{1, *}$, Ekaterina Alekseeva ${ }^{2}$, Aleksey Lukianov ${ }^{3}$ and Pär G. Jönsson ${ }^{1}$ \\ ${ }^{1}$ KTH Royal Institute of Technology, Materials Science and Engineering Department, Brinellvägen 23, SE-100 44 Stockholm, Sweden \\ ${ }^{2}$ St.Petersburg Peter the Great Polytechnical University, St.Petersburg, Russia \\ ${ }^{3}$ Stupino Metallurgical company, Stupino, Russia
}

\begin{abstract}
It is known that non-metallic inclusions (NMI) that are formed during steel production and heat treatment can significantly affect the properties of final steel products. Therefore, it is very important to be able to determine the content of harmful NMI in steels. Nickel-based alloys are widely used in the oil and gas recovery industry, due to a good combination of strength and corrosion properties. Earlier studies have shown that the corrosion properties in immersion test and electrochemical tests for Ni-based EP718 alloys are slightly lower than that for 718 alloys. The focus in this study was the influence of different NMI on the corrosion resistance of these alloys. The characteristics of inclusions (such as size, morphology, and chemical composition) were analysed by using the electrolytic extraction method followed by threedimensional investigations using SEM in combination with EDS. It was found that some non-metallic inclusions in EP718 alloys significantly reduce its corrosion resistance. It was also shown that a primary dissolution of the metal matrix occurs around certain inclusions during electrolytic extraction. Based on obtained results, the corrosion active non-metallic inclusions can be determined in these Nickel-base alloys and some recommendations for optimization of their production technology can be formulated.
\end{abstract}

\section{Introduction}

It is known that non-metallic inclusions (NMI) that are formed during steel production and heat treatment can significantly affect the properties of final steel products (such as workability, mechanical properties, corrosion resistance, etc.). Therefore, it is very important to be able to determine the content of harmful NMI in steels and to evaluate their behaviour during steelmaking processes to reach excellent properties in steel products.

Nickel-base alloys are widely used in the oil and gas recovery industry due to a good combination of strength and corrosion properties. Earlier studies [1] have shown that the corrosion properties in immersion test and electrochemical tests for Ni-based EP718 alloy are slightly lower than that for alloy 718 . At the same time, it has been found that various non-metallic inclusions observed on polished metal samples of EP718 alloys can significantly reduce its corrosion resistance. However, more detailed studies are necessary to determine the most corrosion-active inclusions.

A number of studies [2-4] performed during the last 10-20 years showed that the three-dimensional (3-D) investigations of inclusions and clusters on a film filter after electrolytic extraction (EE) from metal samples have major advantageous in comparison to the conventional two-dimensional (2-D) investigations of NMI on polished surfaces of metal samples. During electrolytic extraction, the metal matrix of sample is dissolved in an electrolyte. The NMI and clusters, which are more stable and did not dissolved during the electrolytic process, can be collected and analysed on a surface of film filter after a filtration of the electrolyte.

This study focused on precise assessments of nonmetallic inclusions in corrosion resistance nickel-based alloys (EP718 and 718) by using the electrolytic extraction method. Based on comparative analysis of inclusions characteristics, the most harmful NMI were determined with respect to the corrosion resistance of the investigated nickel-based alloys.

\section{Experimental Procedures}

\subsection{Steel production and sampling}

Metal samples obtained from two industrial Ni-based alloys (Russian alloy EP718 and alloy 718) were used for detailed investigations of non-metallic inclusions and their corrosion activities. Both alloys were produced by using a double re-melting procedure followed by forging. The chemical compositions of both alloys are given in Table 1.

Table 1. Contents of main elements in Ni-based alloys (wt $\%)$.

\footnotetext{
${ }^{*}$ Corresponding author: karasev@kth.se
} 


\begin{tabular}{|c|c|c|}
\hline Alloy & $\begin{array}{c}\text { EP718 } \\
\text { (TU14-13905-85) }\end{array}$ & $\begin{array}{c}\text { Inconel 718 } \\
\text { (API 6A718) }\end{array}$ \\
\hline $\mathrm{C}$ & $\leq 0.1$ & $\leq 0.045$ \\
\hline $\mathrm{Ni}$ & $43.0-47.0$ & $50-55$ \\
\hline $\mathrm{Cr}$ & $14.0-16.0$ & $17-21$ \\
\hline $\mathrm{Nb}$ & $0.8-1.3$ & $4.8-5.2$ \\
\hline $\mathrm{Mo}$ & $4.0-5.2$ & $2.8-3.3$ \\
\hline $\mathrm{Ti}$ & $1.8-2.4$ & $0.8-1.15$ \\
\hline $\mathrm{W}$ & $2.5-3.5$ & - \\
\hline $\mathrm{Al}$ & $0.9-1.4$ & $0.4-0.6$ \\
\hline $\mathrm{S}$ & $\leq 0.01$ & $\leq 0.01$ \\
\hline \multicolumn{2}{|c|}{}
\end{tabular}

Metal samples for assessment of NMI were cut after heat treatments of alloys, according to requirements of corresponding standards. Detailed descriptions of production technology and corrosion tests are given in a previous article [1].

\subsection{Evaluation of the non-metallic inclusions}

Metal samples from both Ni-based alloys were used for three-dimensional (3-D) investigations of non-metallic inclusions extracted using the electrolytic extraction (EE) technique. The electrolytic extractions were done in the KTH Royal Institute of Technology (Stockholm, Sweden) by using the following extraction parameters: electrolyte - 10\%AA (10\% acetylacetone- $1 \%$ tetramethyl-ammonium chloride-methanol); electric current 40 60 mA; voltage 2.9 3.8 V. After an electrolytic dissolution of metal matrix, the non-metallic inclusions, which did not dissolve in the given electrolyte, were collected on a surface of a membrane polycarbonate film filter (having a $0.4 \mu \mathrm{m}$ open-pore diameter) during filtration of the electrolyte after the completed EE. The weight and depth of the metal matrix layer dissolved during EE process were 0.081 0.093 g and 73 97 $\mu \mathrm{m}$, respectively.

The characteristics of inclusions (such as size, morphology, and chemical composition) were analysed by using a scanning electron microscope (SEM) combined with energy dispersive spectroscopy (EDS). The NMI were investigated on film filters and on surfaces of metal samples after EE. Typical SEM images of non-metallic inclusions observed on a film filter and on a surface of metal sample after electrolytic extraction are shown in Figure 1.

(a)
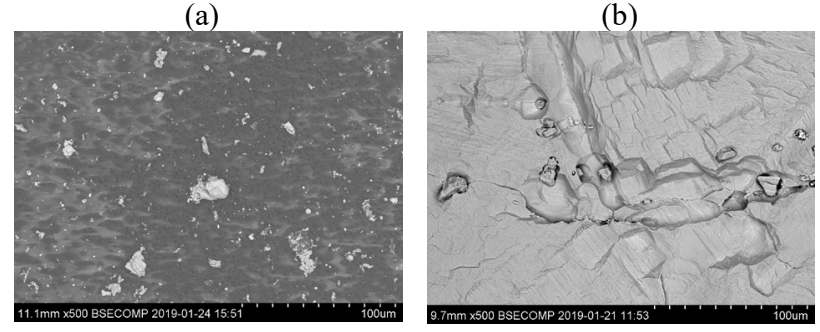

Fig. 1. SEM images of NMI observed on film filter (a) and on metal surface (b) after electrolytic extraction.

\subsection{Characterization of NMI on film filters after electrolytic extraction}

Results obtained from 3-D investigations of NMI on film filter show that the EP718 alloy contains a wide variety of undesirable non-metallic inclusions, including complex carbides of titanium, niobium, molybdenum and tungsten, titanium and niobium nitrides, titanium sulphides. The typical inclusions observed on film filter after EE of the EP718 alloy were classified into four groups based on the composition and morphology. Typical SEM images, contents of main elements and size ranges for different types of inclusions are shown in Table 2. It should be noted that the contents of light elements (such as $\mathrm{C}, \mathrm{N}$ and $\mathrm{O}$ ) cannot be precisely determined by EDS. Therefore, these values were not present in this table.

Table 2. NMI observed on film filter after EE of EP718.

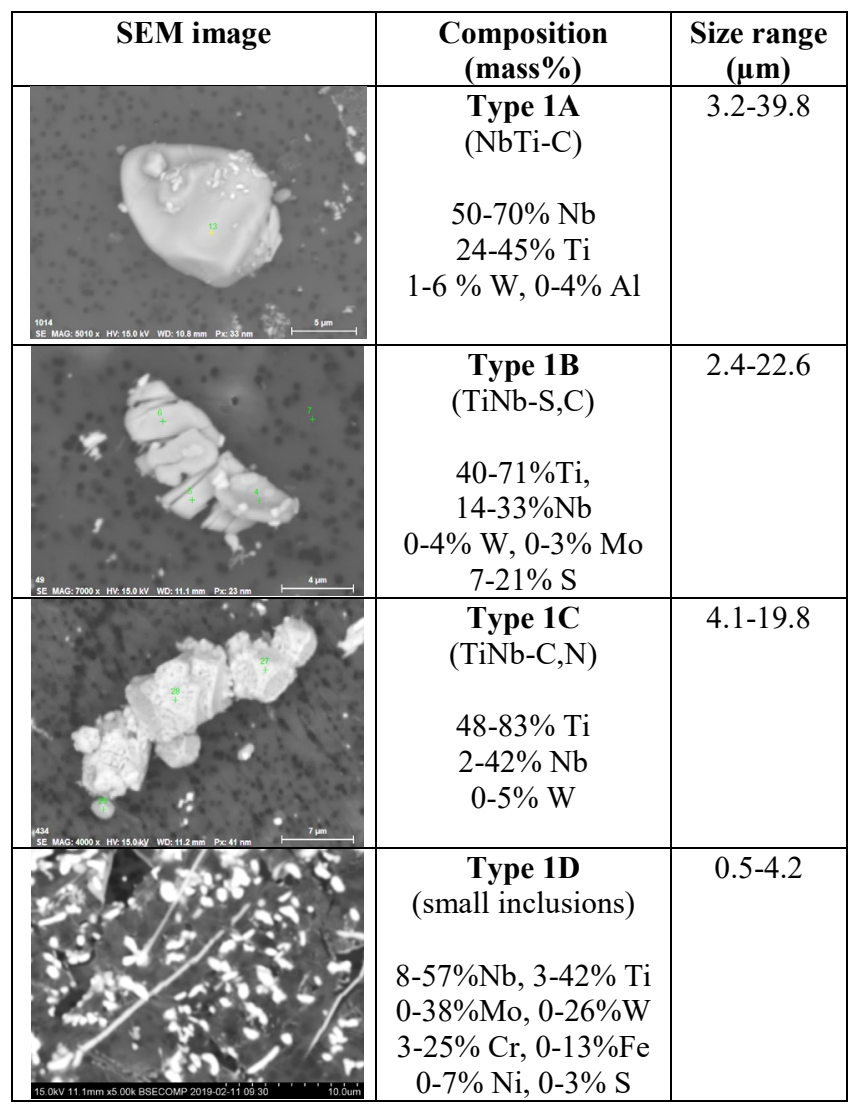

It was found that Types $1 \mathrm{~A}, 1 \mathrm{~B}$ and $1 \mathrm{C}$ inclusions include both single inclusions and clusters (having sizes up to $40 \mu \mathrm{m}$ ). Moreover, the Type $1 \mathrm{~B}$ sulphides (TiNb$\mathrm{S}, \mathrm{C})$ are present mostly as thin plates with a thickness of 1-2 $\mu \mathrm{m}$. However, these inclusions were recognized in a previous article [1] as "needles", based on 2-D investigations on polished surfaces of the metal samples. The Type 1D inclusions include small size (0.5-4.2 $\mu \mathrm{m})$ carbides, which contain $\mathrm{Nb}, \mathrm{Ti}, \mathrm{Mo}, \mathrm{W}, \mathrm{Cr}, \mathrm{Fe}$ and $\mathrm{Ni}$. Some of these small inclusions also contain small amounts of sulphur. In this study, Type 1D was assumed to include all small inclusions having different morphologies (spherical, irregular and needles).

\section{Results and Discussions}


The 718 alloy contains only carbides and nitrides of titanium and niobium. The typical inclusions observed on film filters after EE of 718 alloy, the contents of main elements, and size ranges for different types of inclusions are shown in Table 3.

Table 3. NMI observed on film filter after EE of 718 alloys.

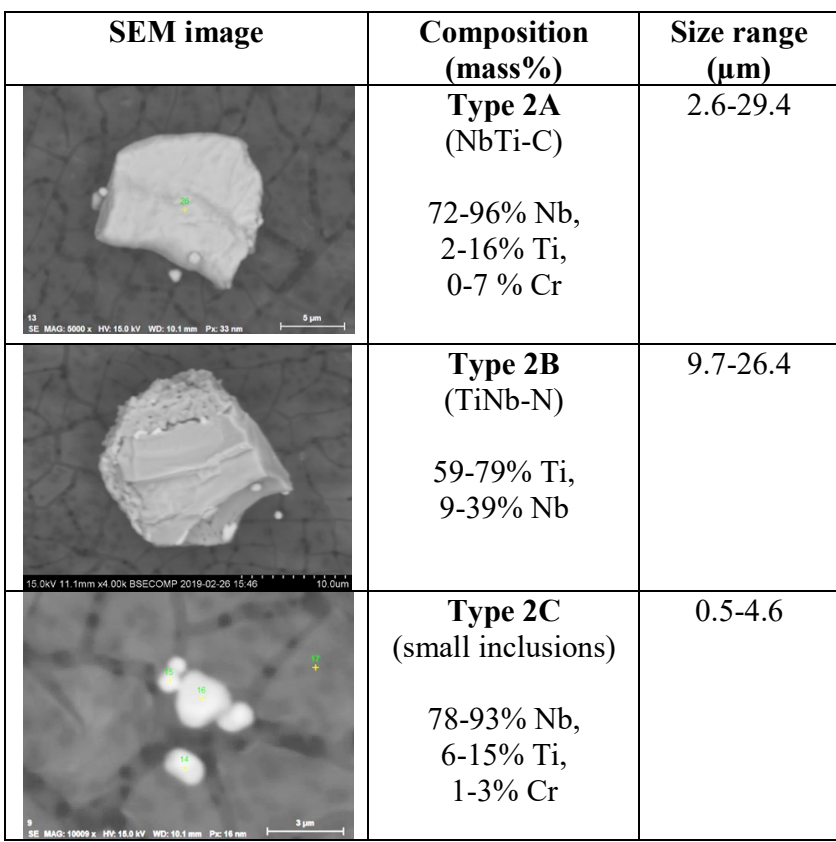

It was found that some NbTi-C inclusions (Type 2A) are present as single inclusions and clusters in the 718 alloy. They have a maximum size of up to $29 \mu \mathrm{m}$.

\subsection{Characterization of NMI on metal surface after electrolytic extraction}

It was observed on metal surfaces after electrolytic extraction that the small size inclusions (Types 1D and $2 \mathrm{C}$ ) in both alloys are located mostly on grain boundaries. Moreover, that other types of large size inclusions can be locate both on grain boundaries and inside metal grains.

It was also found that the dissolution of the metal matrix around different inclusions during electrolytic extraction did not occur uniformly, as shown in Figure 2. Relatively big craters/ditches were observed around some specific inclusions and clusters, while the metal matrix around other inclusions was dissolved more uniformly (Fig. 2b). It was assumed that these craters and ditches are formed on metal surface due to the electro-chemical dissolution of the weakened metal matrix around corrosion-active NMI during electrolytic extraction. It should be pointed out that the $10 \% \mathrm{AA}$ electrolyte does not dissolve the observed non-metallic inclusions. Therefore, it may be safely suggested that the investigated inclusions were not involved directly in the electro-chemical process of dissolution of the metal matrix around these inclusions. (a)

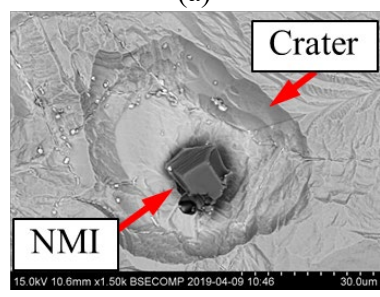

(b)

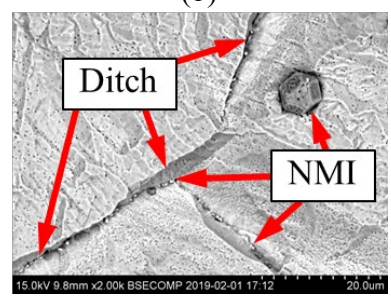

Fig. 2. SEM images of dissolution of metal matrix NMI around different inclusions and clusters observed on the metal surface after electrolytic extraction.

The dissolution extent of the metal matrix around different inclusions was evaluated by using a dissolution coefficient $\left(K_{D}=A_{C} / A_{N M I}\right)$, which was calculated as the ratio between the area of crater $\left(A_{C}\right)$ around an inclusion and the area of this inclusion $\left(A_{N M I}\right)$ measured on a SEM image. The average values of $K_{D}$ and ranges of equivalent diameters of craters around inclusions $\left(D_{e q}=\right.$ $\left.\left(4 \cdot A_{C} / \pi\right)^{1 / 2}\right)$ for different types of inclusions in both alloys are given in Table 4.

Table 4. Average dissolution coefficient values of metal matrix $\left(K_{D}\right)$ and size ranges of craters around different NMI observed on metal surfaces after EE of both alloys.

\begin{tabular}{|c|c|c|}
\hline Type of NMI & Aver. $\boldsymbol{K}_{\boldsymbol{D}}{ }^{*}$ & Size range, $\boldsymbol{D}_{\boldsymbol{e q}}(\boldsymbol{\mu m})$ \\
\hline Type 1A & 2.35 & $5.9-24.4$ \\
$($ NbTi-C) & $(4.86)$ & $(16.2-39.5)$ \\
\hline Type 1B & - & - \\
$($ TiNb-S,C) & $(8.75)$ & $(15.4-39.7)$ \\
\hline Type 1C & 2.78 & $8.7-10.1$ \\
$($ TiNb-C,N) & $(-)$ & $(-)$ \\
\hline Type 1D & - & - \\
(small inclusions) & $(21.30)$ & $(8.4-12.3)$ \\
\hline Type 2A & 2.23 & $5.6-21.2$ \\
(NbTi-C) & $(5.14)$ & $(11.4-39.9)$ \\
\hline Type 2B & 2.41 & $17.3-26.0$ \\
(TiNb-N) & $(3.38)$ & $(24.4-36.3)$ \\
\hline Type 2C & - & - \\
(small inclusions) & $(5.17)$ & $(2.1-7.1)$ \\
\hline
\end{tabular}

*: $(.$.$) - values for NMI located on grain boundaries.$

According to the obtained results, it was found that the small size inclusions (Type 1D) on grain boundaries of EP718 alloy have the largest average dissolution coefficient (21.3). It can be explained by depletion zones caused by corrosion-resistant elements (such as $\mathrm{Cr}$, Mo and $\mathrm{Ni}$ ) in the metal matrix around these inclusions precipitated on grain boundaries. However, the crater/ditch size around these small inclusions $(<5 \mu \mathrm{m})$ is relatively small $\left(D_{e q}<13 \mu \mathrm{m}\right)$ compared to other types of NMI in this metal sample. It should be pointed out that the largest sizes of craters (up to $40 \mu \mathrm{m}$ ) were observed in EP718 alloy samples around Types 1B (TiNb-S,C) and 1A (NbTi-C) inclusions located on grain boundaries. The average $K_{D}$ values for these types of inclusions are 8.75 and 4.86 , respectively.

In the 718 alloy, the small size inclusions (Type 2C) and $\mathrm{NbTi}-\mathrm{C}$ inclusions (Type 2A) on grain boundaries have largest average dissolution coefficients $(\sim 5.2)$. However, largest sizes of craters in this metal sample were observed around Type 2A (up to $40 \mu \mathrm{m}$ ) and Type 
2B (up to $36 \mu \mathrm{m}$ ) inclusions located on grain boundaries. It is interesting that the $K_{D}$ values for inclusions located on grain boundaries are 1.4-2.3 times larger compared to the respective inclusions located inside of grains in both alloys.

Overall, the use of the electrolytic extraction method in combination with 3-D investigations of NMI by using SEM/EDS shows that more accurate information can be obtained with respect to the morphology, chemical composition and size of inclusions in the EP718 and 718 alloys. Based on additional results obtained after EE of metal samples, more harmful non-metallic inclusions regarding corrosion of metal matrix can be detected in these Nickel-base alloys. As a next step, the reasons for formations of more harmful non-metallic inclusions in these Nickel-base alloys can be considered. Furthermore, some recommendations for optimization of the production technology can be formulated.

\section{Conclusions}

The electrolytic extraction method was applied for evaluation of non-metallic inclusions in corrosion resistance nickel-based alloys (EP718 and 718). Based on a comparative study of the inclusions characteristics (such as size, morphology, and chemical composition) in both alloys, the following conclusions can be done:

1. The electrolytic extraction method can successfully be applied for precise 3-D investigations of different NMI and clusters in Ni-based alloys.

2. The 3-D investigations of NMI on film filter and on metal surface after EE showed that both alloys contain different single inclusions as well as clusters (having a size up to $40 \mu \mathrm{m}$ ). Moreover, the sulphides (Type 1B) in the EP718 alloy are present mostly as thin plates with a thickness of 1-2 $\mu \mathrm{m}$, which were determined as "needles" from 2-D investigations on a polished surface of the metal samples in previous study.

3. Observation of NMI on metal surfaces of samples after EE showed that relatively big craters/ditches were observed around some specific inclusions and clusters, while metal matrix around other inclusions was dissolved more uniformly. The largest sizes of craters (up to $40 \mu \mathrm{m}$ ) were observed in EP718 alloy around of TiNb-S,C clusters (Types 1B) and NbTi-C (Type 1A) inclusions and clusters located on grain boundaries. The largest sizes of craters in 718 alloy were observed around of NbTi-C (Type 2A) inclusions and clusters (up to $40 \mu \mathrm{m}$ ) and around of $\mathrm{TiNb}-\mathrm{N}$ (Type 2B) inclusions (up to $36 \mu \mathrm{m}$ ) located on grain boundaries.

4. The dissolution coefficients of the metal matrix around inclusions $\left(K_{D}\right)$ are 1.4-2.3 times larger for NMI located on grain boundaries compared to the respective inclusions located inside the grains, in both alloys.

\section{References}

1. A. A. Khar'kov, A. V. Shakhmatov, E. L. Gyulikhandanov, and E. L. Alekseeva, Chemical and Petroleum Engineering, 54 (2019), Nos.9-10, 771-778.

2. A.V.Karasev and H. Suito, Metall. Mater. Trans. B, 30 (1999), 259-270.

3. Y. Kanbe, A. Karasev, H. Todoroki, P.G. Jönsson, ISIJ Int., 51 (2011), 593-602.

4. A. Karasev, P.G. Jönsson, 5th Int. Conf. on Process Development in Iron and Steelmaking SCANMETV, Luleå, Sweden, (2016). 